\title{
Elaboração de modelos estruturais para aperfeiçoamento da didática em Resistência dos Materiais.
}

DOI: 10.37702/2175-957X.COBENGE.2021.3479

Geysiane Faria Barros Milagres - geysiane.milagres@ufv.br Universidade Federal de Viçosa

Rua São Vicente 20

36576-434 - Viçosa - MG

Diôgo Silva de Oliveira - diogooliveira@ufv.br Universidade Federal de Viçosa

Av. P. H. Rolfs, Campus Universitário s/n

36570-900 - Viçosa - MG

José Carlos Lopes Ribeiro - jcarlos.ribeiro@ufv.br Universidade Federal de Viçosa

Av. P. H. Rolfs $s / n$

36571-000 - Viçosa - MG

ELAINE SOARES BRITO - elaine.soares@ufv.br

Universidade Federal de Viçosa

Rua Minas Gerais 3124

35171-314 - Coronel Fabriciano - MG

Nilo de Oliveira - nilo.ess@gmail.com

Universidade Federal de Viçosa

Rua Cariacica 150

29830-000 - NOVA VENECIA - ES

Diego Dias Veloso - diego.dias@ufv.br

Universidade Federal de Viçosa

Rua Santo Agostinho 567

31035-480 - Belo Horizonte - MG

Resumo: No ensino de engenharia nas universidades é essencial o uso de demonstrações que associem o ensino teórico às situações práticas vivenciadas pelos profissionais da engenharia. Tal enfoque precisa ser aprimorado na disciplina 
de Resistência dos Materiais, correlacionando a parte matemática com o uso prático de modelos estruturais. Assim, teve-se como objetivo a confecção de modelos de ligações estruturais para levar aos alunos uma explicação da teoria, facilitando o entendimento dos conceitos de ação, esforços solicitantes, tensão, seção crítica, seção bruta e área líquida, facilitando a visualização dos esforços que surgem nas estruturas, bem como avaliar o uso dessa metodologia de ensino. Foram modeladas peças que representam diferentes modelos estruturais utilizando o software AutoCAD 3D e realizada a posterior impressão 3D. Após finalizadas, essas foram utilizadas para explicações em sala de aula para alunos da disciplina de Resistência dos materiais, definindo e esclarecendo os conceitos da disciplina. Foi aplicado um questionário para avaliar a efetividade da metodologia a 36 alunos, sendo a maioria dos cursos de Engenharia Civil e Mecânica, cursando o 5 o período e com domínio prévio do assunto. Grande parte dos alunos consideraram as peças boas ou ótimas para o entendimento teórico e consideram que peças devem continuar a serem usadas na disciplina. Assim, notou-se que os modelos facilitaram o entendimento dos esforços nas diferentes ligações, bem como de conceitos básicos e fundamentais para disciplinas futuras de estruturas, e que o uso de aulas práticas e expositivas são eficientes e devem continuar sendo realizadas.

Palavras-chave: Educação, Engenharia, Estruturas, Resistência dos Materiais 


\section{INTRODUÇÃO}

No cenário atual do ensino de Engenharia, a relação dos alunos com a captação de novas informações tem sido cada vez mais marcada pela presença de equipamentos multimídia, que facilitam a visualização e a interação com os fenômenos físicos e mecânicos, o que contribui muito para o processo de aprendizagem. O campo de ensino prático, em sua maioria, fica restrito à necessidade de estruturas laboratoriais e geralmente estão associadas a elevados custos e equipamentos específicos para sua realização. Quando essa vivência prática não é possível, fica a cargo do aluno a necessidade de abstrair para formar uma compreensão tridimensional, já que dentro da sala de aula, o conteúdo geralmente é abordado de forma bidimensional (quadros e telas).

No curso de Engenharia Civil e demais Engenharias voltadas ao dimensionamento de estruturas, o ensino da Resistência dos Materiais tem sido um grande desafio por parte dos professores. Por ser uma das primeiras disciplinas do curso a tratar dos conceitos de tensões e deformações, os alunos têm dificuldade em visualizar as seções críticas onde essas tensões atuam. Mesmo com recursos multimídia dentro de sala de aula, como as projeções em Datashow, fica faltando o aspecto prático para a visualização dos fenômenos mecânicos. Por parte dos alunos, falta o elemento "manusear" e interagir com a estrutura.

Brendler et al. (2014) afirmam que a elaboração de recursos didáticos táteis serve de apoio visual tridimensional que poderá ser utilizado em qualquer circunstância de ensino. Os recursos didáticos táteis auxiliam tanto ao aluno como ao professor de diferentes formas e medidas. Ao aluno serve como recurso específico, como ferramenta compensativa. Para o professor, como um suporte didático e uma ferramenta para produção de material formativo que servirá às necessidades de seu aluno.

Conforme Barreto (2009), no processo ensino-aprendizagem, o que é transmitido é fundamental, mas a forma como é transmitido, é essencial. Não se propõe mais a responsabilidade da aprendizagem exclusivamente ao aluno, tampouco ao professor, enquanto detentor do saber, como era considerado décadas atrás.

Saramago (2011) comenta sobre a necessidade da criação de modelos qualitativos para que os alunos consigam melhor compreender o funcionamento da estrutura. Além disso, a manipulação dos modelos por parte dos estudantes e a adoção de materiais flexíveis na construção desses modelos permitiu aos alunos observar as deformadas da estrutura e identificar as regiões tracionadas e comprimidas. A pesquisadora ressalta que o processo de ensino teórico, que chamou de "Informação verbal", é deficitário quando dissociado da vivência prática. Se houver deficiências no seu processo educativo, os profissionais da engenharia ficam comprometidos de exercer plenamente a sua prática, limitando sua capacidade de intervir criticamente no campo sob sua responsabilidade.

Quando a vivência experimental não é possível, uma alternativa é a utilização de modelos que possam ser levados com facilidade para dentro da sala de aula. Oliveira (2008) comenta que o uso de modelos estruturais qualitativos tem um papel importante no desenvolvimento da engenharia, sendo uma aplicação essencial no processo de ensino, o seu uso na educação. Oliveira (2008) também verificou que o manuseio e montagem de modelos qualitativos mostrou-se muito importante na compreensão do comportamento das estruturas analisadas, pois aproxima a grandeza dos fenômenos analisados à percepção dos sentidos humanos, uma vez que em estruturas reais as deformações e deslocamentos são incapazes de serem percebidos sem a utilização de aparelhos especiais. 
Assim, Rabello e Leite (2015) afirmam que o manuseio de tais modelos, que representam qualitativamente os fenômenos físicos das estruturas, incentiva o aluno ao hábito de se realizar uma observação do entorno, bem como desenvolve seu pensamento crítico e a formulação de conclusões próprias. Deve-se também destacar a importância da parte matemática do dimensionamento, que tem papel primordial no ensino da estrutura, porém, deve ser inserida no momento certo, quando o aluno já possuir o domínio do fenômeno físico, e for então capaz de traduzi-lo na linguagem matemática.

Considerando essa necessidade, o presente trabalho traz a proposta metodológica da utilização de modelos estruturais produzidos em impressora 3D, que representam ligações típicas em estruturas abordadas no processo de ensino de Resistência dos Materiais. Pretende-se com esse trabalho, contribuir com o processo de visualização das seções críticas e criar um processo de interação dos alunos com os mecanismos de ruptura.

\section{IMPRESSÃO 3D}

A impressão 3D, também conhecida na indústria como manufatura aditiva, na qual os objetos são construídos pela adição de camadas sucessivas, teve seu primeiro registro com o trabalho de Kodama (1981). Esse autor propôs um sistema de prototipagem rápida que consistia em expor fotopolímeros líquidos a raios ultravioleta, de modo a solidificar camada por camada. A partir desse trabalho, a manufatura aditiva ganhou campo na indústria e nas instituições de pesquisa, o que permitiu o desenvolvimento de novos materiais para impressão, envolvendo uma variada gama de polímeros, metais, cimentícios e cerâmicos. Esse avanço culminou no desenvolvimento de impressoras 3D de pequeno porte para uso doméstico, por volta do ano de 2011 (MARTINS, 2017). Grande parte dessas impressoras utilizam a técnica de Modelagem por Deposição de Material Fundido (FDM Fused Deposition Modeling), em que o material é fundido junto da cabeça de impressão e depositado em camadas, para que ocorra a cura e ou resfriamento. A impressora utilizada para confecção do presente trabalho é apresentada na Figura 1.

Figura 1 - Impressora 3D por FDM para material polimérico

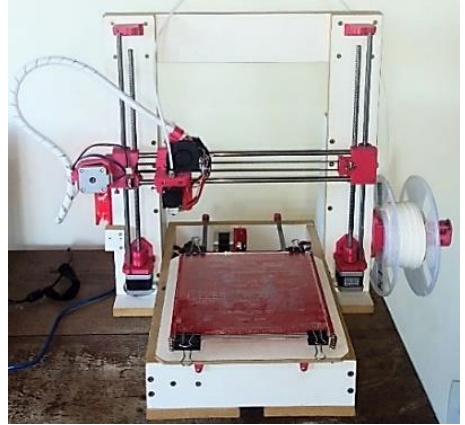

Fonte: Os autores.

Atualmente, a impressão 3D já se faz uma realidade acessível a todos que queiram usar essa técnica de produção, com impressoras 3D, para materiais poliméricos, de custo inferior a $\mathrm{R} \$ 2.000,00$. Para os usuários que queiram ir além, é possível construir sua própria impressora, utilizando plataformas Open Source, com custo inferior ao mencionado.

Queiroz et al. (2020) utilizaram a impressão 3D na elaboração de modelos didáticos como ferramenta de facilitação do processo ensino-aprendizagem na disciplina de estruturas de aço. Constataram que, quando utilizadas de forma planejada, nos momentos 
adequados e de acordo com os objetivos da aula, as impressões 3D constituem uma poderosa ferramenta facilitadora do aprendizado. A utilização das peças confeccionadas possibilitou aos discentes uma aproximação da realidade dos projetos de estruturas metálicas durante as aulas, que são predominantemente teóricas.

De acordo com Palaio et al. (2018), o uso da impressão 3D no desenvolvimento de modelos didáticos mostrou ser um método bastante eficaz para fornecer o apoio ao conteúdo presente nos materiais de estudo tradicionais, em que os autores propuseram representações tridimensionais de organismos microscópicos tais como as microalgas e cianobactérias. As estruturas evidenciadas mostraram-se perceptíveis ao tato e auxiliaram na identificação dos gêneros e espécies selecionados, tendo um potencial uso para o ensino de ciências para diversos níveis escolares.

Adicionalmente, uma das maiores vantagens da impressão 3D na criação dos modelos didáticos é sua capacidade de distribuição e sua facilidade de produção. Os modelos podem ser obtidos por qualquer pessoa que tenha uma impressora 3D, permitindo até que sejam feitas várias cópias idênticas do mesmo modelo. Ressalta-se também a boa resistência dos materiais como PLA, ABS, dentre outros, além de permitirem precisão e qualidade dos modelos impressos. A grande maioria das impressoras de uso doméstico trabalha com camadas de $0,25 \mathrm{~mm}$ de espessura, podendo chegar a até $0,1 \mathrm{~mm}$ de espessura.

Knill e Slavkovsky (2013, p.12, apud AGUIAR, 2016, tradução dos autores) comentam que "a nova e ainda tecnologia de ponta (a impressão 3D) possibilita a todos construir modelos para a sala de aula". Lipson (2007, p.1, apud AGUIAR, 2016, tradução dos autores) diz ainda que a impressão 3D "possibilita a fabricação de formas tridimensionais complexas sem a necessidade de habilidades especiais de manufatura, ferramental e recursos; portanto, possibilita educadores a desenhar facilmente e tornar real qualquer modelo".

De acordo com Aguiar (2016), as impressoras 3D também são ferramentas e, portanto, faz-se necessário desenvolver habilidades para operá-las com sucesso. $O$ autor mencionou que muitos dos professores do projeto relataram que demoraram alguns meses para se familiarizarem com a impressora 3D e o seu software associado, e assim conseguirem usá-los com sucesso e confiança no ensino.

Martins (2017) comenta que a impressão 3D proporcionará a democratização da produção e eventualmente a eliminação da dependência dos países menos desenvolvidos dos mais desenvolvidos relativamente à capacidade produtiva, assim como uma maior funcionalidade do produto final, pois estará altamente customizado e direcionado para o consumidor final. Além disso, a impressão 3D provocou a descentralização da produção com impacto nas necessidades de transporte, uso mais eficiente das matérias primas, diminuição do desperdício e diminuição no número de ferramentas para fabricação.

Por outro lado, Onisaki e Vieira (2019) ressaltam que não bastam iniciativas que venham a instrumentalizar as escolas com impressoras 3D e viabilizar cursos meramente técnicos a professores se não forem articuladas ações para a ampliação cultural dos docentes. É preciso saber em que aplicar e como aplicar. É necessário buscar e desenvolver metodologias sobre como inserir esse novo ferramental dentro do ambiente de ensino a fim de gerar ganhos efetivos no processo de aprendizagem.

\section{RESISTÊNCIA DOS MATERIAIS}


Como abordado em referências clássicas como Timoshenko (1983), Hibbeler (2010), Beer e Johnston (2011), dentre outros, a Resistência dos Materiais é a área da Mecânica que trata da relação entre as forças externas aplicadas a um corpo e a distribuição dos esforços internos (tensões) gerados, provocando deformações nesse corpo. Com isso é possível analisar e dimensionar estruturas, definindo materiais constituintes, geometria e condições de apoio e de carregamento. No que tange à distribuição de esforços internos, existe uma grande dificuldade por parte dos alunos em visualizar as seções internas definidas como críticas e identificar o tipo de tensão que atua nessas seções.

A seção crítica, conforme Beer e Johnston (2011), é aquela onde ocorre no componente estrutural alguma descontinuidade, um furo ou uma brusca mudança de direção, em que podem ocorrer valores altos de tensões localizadas. Imaginando uma chapa de seção transversal retangular, a seção bruta, conforme Pinheiro (2005), é dada pelo produto entre a largura bruta e a espessura da peça, sendo, portanto, a própria seção transversal da peça. Por sua vez, a área líquida, de acordo com Pfiel e Pfiel (2009) é dada subtraindo-se da área bruta a área de furos contidos em uma seção reta da peça.

São esses os conceitos preliminares e indispensáveis que este projeto tem o intuito de passar para os estudantes, colaborando com o conteúdo futuro tanto da disciplina de Resistência dos Materiais, quanto das demais disciplinas de estruturas dos cursos de engenharia, que abordam desde os cálculos básicos, até as análises estruturais e o dimensionamento de projetos.

\section{METODOLOGIA}

Demonstrar os planos e seções críticas em elementos estruturais consiste em um dos intuitos desse projeto, de forma a facilitar a visualização de como os esforços atuam e se distribuem nas seções, para que possam então ser verificadas.

No Laboratório de Resistência dos Materiais da UFV - Universidade Federal de Viçosa, durante o $2^{\circ}$ semestre de 2019, foram confeccionados modelos digitais 3D de peças estruturais utilizando o software AutoCAD 3D 2019. Essas peças foram posteriormente impressas em plástico com uso de uma impressora 3D do próprio laboratório, com a finalidade de serem utilizadas na disciplina CIV 150 - Resistência dos Materiais I.

Após a impressão, as peças foram presas por meio da colagem de imãs, de forma a representarem ligações estruturais. As peças finalizadas foram usadas em sala de aula de forma prática e demonstrativa após a explicação teórica sobre o conteúdo em questão, para demonstrar as tensões que surgem nos diferentes tipos de ligações, bem como as formas de ruptura.

A explanação foi feita a 36 alunos da disciplina CIV 150 de variados cursos de engenharia da Universidade. Posteriormente, as peças foram disponibilizadas para o manuseio dos alunos. Finalmente, foi aplicado um questionário, a fim de coletar dados sobre a eficácia do projeto em cumprir o objetivo para o qual foi concebido. O questionário foi elaborado com 11 questões, sendo as 10 primeiras de múltipla escolha e 1 aberta para que os alunos deixassem por escrito sugestões para as peças.

As questões a serem respondidas foram:

1. Qual o seu curso?

2. Qual o período está cursando?

3. Você já possui algum conhecimento prévio do assunto abordado pelas peças?

4. De 1 a 5 (sendo 1 "ruim" e 5 "ótimo"), quanto você acha que as peças contribuíram no entendimento e visualização dos esforços?

5. Você acha que as peças deveriam continuar a serem utilizadas na disciplina? 
6. Sabendo-se que cada peça demonstra um tipo de esforço, de 1 a 5 (sendo 1 "ruim" e 5 "ótimo"), quanto você acha que o formato com que cada uma delas foram confeccionadas cumprem esse objetivo?

7. De 1 a 5 (sendo 1 "ruim" e 5 "ótimo"), quanto você acha que a utilização das peças possui relação com a teoria que foi previamente explicada?

8. Houve o surgimento de muitas dúvidas durante a exposição das peças?

9. De 1 a 5 (sendo 1 "ruim" e 5 "ótimo"), em quanto você classificaria a qualidade das peças?

10. Você acha que confeccionar as peças foi uma ruim, deficitária, razoável, boa ou ótima (em escala de 1 a 5) opção para a demonstração prática em sala de aula?

11. Você possui alguma sugestão do que melhorar nas peças? Se sim, deixe um comentário abaixo.

Após a aplicação e obtenção de respostas dos alunos, foi feita a catalogação dos resultados obtidos, no qual se realizou toda a contagem e armazenamento dos resultados. Já com relação as questões abertas, foram armazenadas as respostas para melhorias futuras nas peças.

\section{$5 \quad$ RESULTADOS}

As peças produzidas no laboratório, conforme a metodologia descrita, tiveram como finalidade a representação de alguns mecanismos de ruptura. Para isso, os estudantes puderam manusear as peças, fazendo com que se rompam em áreas pré-estabelecidas, visualizando assim as áreas que influenciam em cada tipo de ruptura que pode ocorrer em estruturas usuais.

A visualização dos tipos de ruptura pôde ser realizada pelos estudantes, considerando as áreas críticas solicitadas por:

a) tensão de cisalhamento simples em seção colada, conforme esquematizado na Figura 2 e visualizado na peça da Figura 3;

b) tensão de cisalhamento simples e duplo em seções críticas com pinos ou parafusos, conforme esquematizado na Figura 4 e na Figura 6 e visualizado nas peças da Figura 5 e da Figura 7;

c) tensão de tração na área líquida, esquematizado na Figura 8 e representado na peça da Figura 9;

d) tensão de cisalhamento longitudinal, conforme esquematizado na Figura 10 e representado na peça da Figura 11;

e) tensão de esmagamento, esquematizado na Figura 12 e representado na peça da Figura 13; e

f) tensões em ligações soldadas, demonstrando o cisalhamento na garganta da solda, esquematizado na Figura 14 e visualizada na peça da Figura 15. 
Figura 2 - Representação de cisalhamento simples em seção colada.

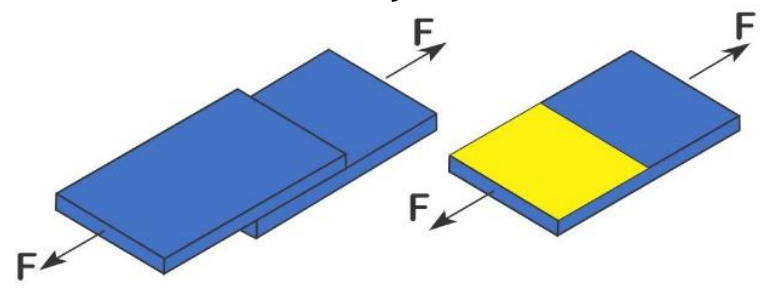

Fonte: os autores.

Figura 4 - Representação de cisalhamento simples em seção com pino.

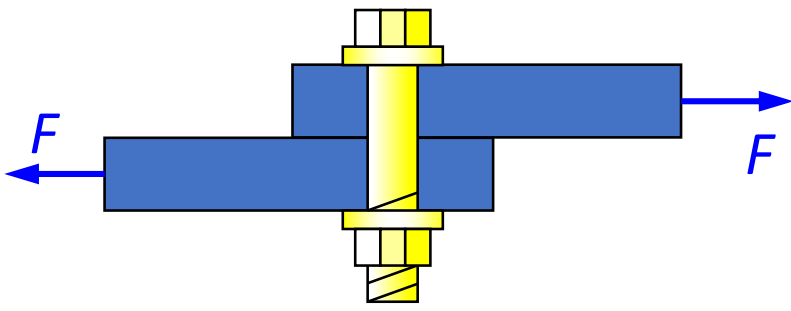

Fonte: os autores.

Figura 6 - Cisalhamento duplo em seção com pino.

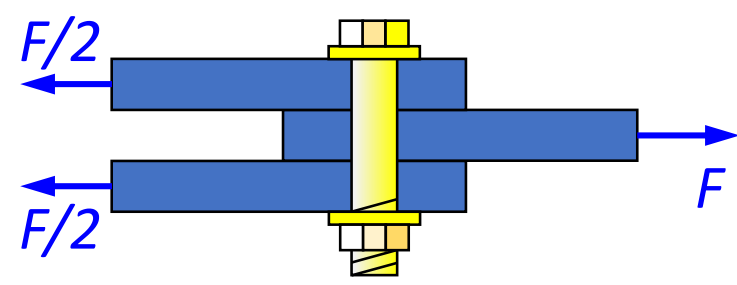

Fonte: os autores.

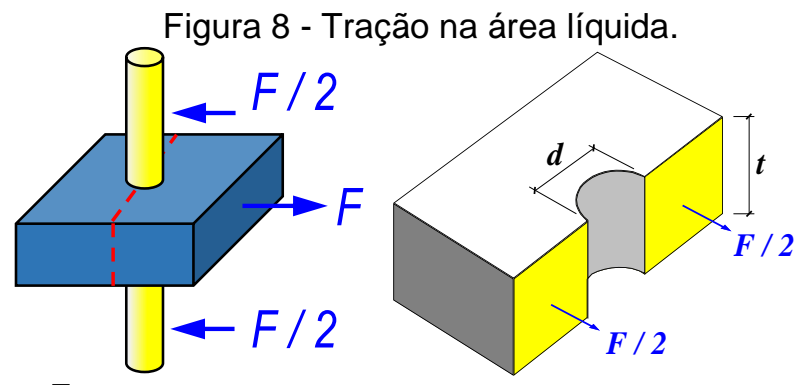

Fonte: os autores.
Figura 3 - Peça representativa de cisalhamento simples em seção colada.
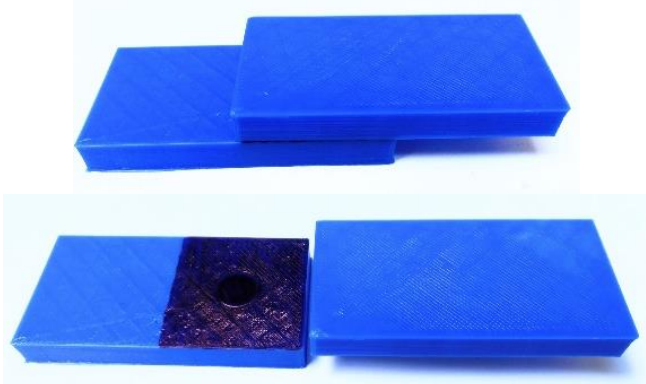

Fonte: os autores.

Figura 5 - Peça representativa de cisalhamento simples em seção com pino.

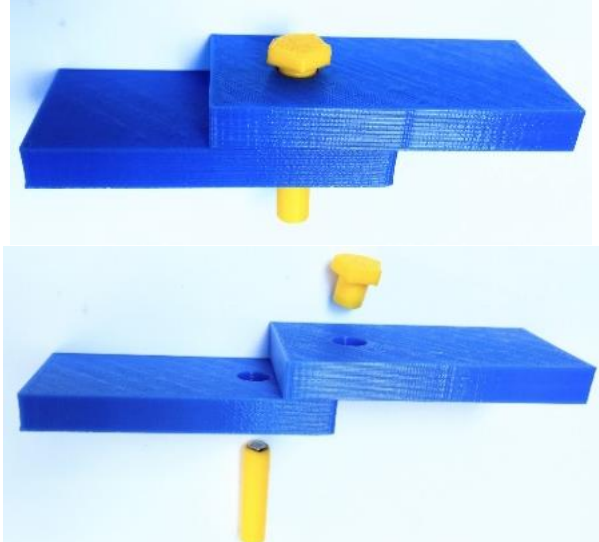

Fonte: os autores.

Figura 7 - Peça representativa de cisalhamento duplo em seção com pino.

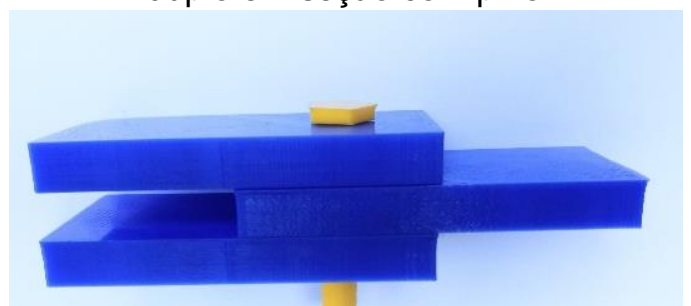

Fonte: os autores.

Figura 9 - Peça representativa de tração na área líquida.

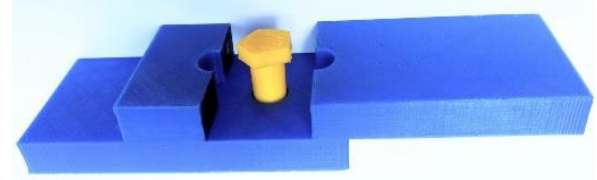

Fonte: os autores. 
Figura 10 - Cisalhamento longitudinal.
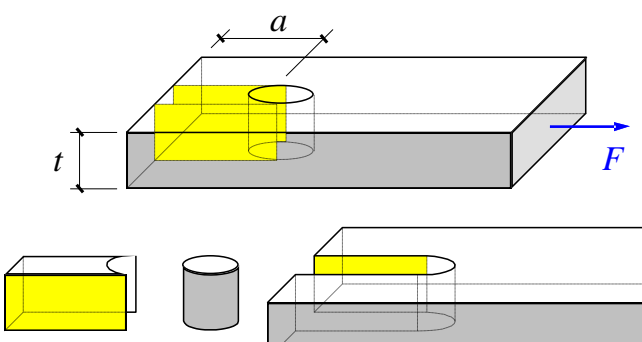

Fonte: os autores.

Figura 12 - Esmagamento.
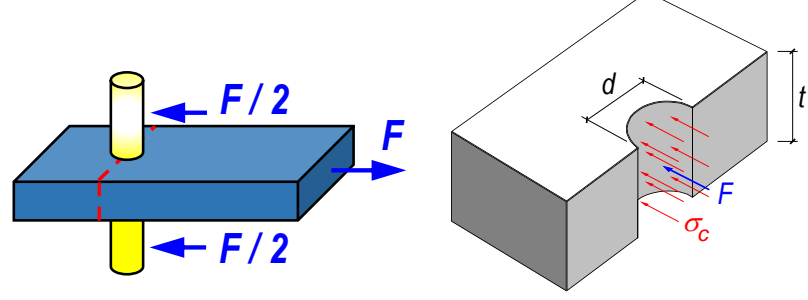

Fonte: os autores.

Figura 14 - Cisalhamento no metal-base e cisalhamento na garganta da solda.

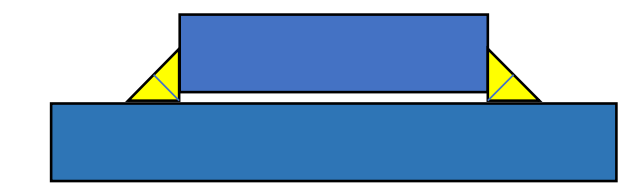

Fonte: os autores.
Figura 11 - Peça representativa de cisalhamento longitudinal.

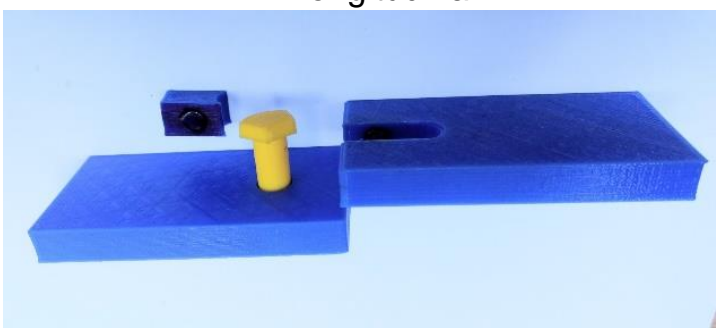

Fonte: os autores.

Figura 13 - Peça representativa de esmagamento.

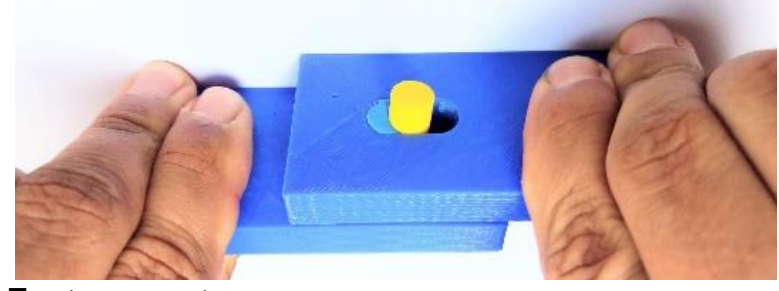

Fonte: os autores.

Figura 15 - Peça representativa de cisalhamento no metal-base e cisalhamento na garganta da solda.

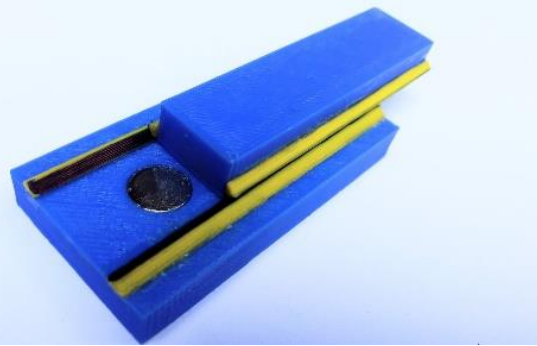

Fonte: os autores.

Com relação aos 36 alunos aos quais o projeto foi apresentado durante a aula de Resistência dos Materiais I, tem-se como resultado do questionário que 17 cursam Engenharia Civil, 17 cursam Engenharia Mecânica e 2 cursam Engenharia Agrícola e Ambiental. Os resultados obtidos a partir das questões de múltipla escolha do questionário aplicado encontram-se na Tabela 1 e na Tabela 2. Pelos resultados mostrados na Tabela 1 , nota-se que grande parte dos estudantes que participaram são dos cursos de Engenharia Civil e Mecânica, cursando o $5^{\circ}$ período, com domínio prévio do assunto tratado pelas peças, que acham que as peças devem continuar a ser usadas na disciplina e que tiveram poucas dúvidas durante a explanação com as peças em sala de aula.

Em relação aos resultados mostrados na Tabela 2, levando-se em consideração a escala adotada de 1, 2, 3, 4 e 5, indicando respectivamente ruim, deficitária, razoável, boa e ótima, para melhor avaliação dos resultados, foram obtidas e analisadas as médias das respostas, obtendo-se os resultados apresentados na Tabela 3.

Portanto, observa-se grande parte das respostas em 4 e 5, ou seja, sendo avaliadas como boas e ótimas, refletindo o eficaz resultado do uso nas peças em sala de aula. Assim pode-se afirmar, com base nos resultados, que as peças são ótimas em contribuir no entendimento e visualização dos esforços; em cumprir o objetivo para o qual foram confeccionadas nos devidos formatos; em relacionar a teoria previamente explicada à utilização das peças; e são boas com relação a sua qualidade, visto que durante o manuseio 
das peças pelos alunos, ocorreu o desprendimento de alguns imãs que eram utilizados para representar as ligações.

Tabela 1 - Resultados das questões fechadas do questionário.

\begin{tabular}{|c|c|}
\hline Alternativas & $\%$ do total de alunos \\
\hline Questão 2 - Qual o período está cursando? \\
\hline Não respondeu & $2,8 \%$ \\
\hline $1^{\circ}$ & $2,8 \%$ \\
\hline $4^{\circ}$ & $13,9 \%$ \\
\hline $5^{\circ}$ & $50,0 \%$ \\
\hline $7^{\circ}$ & $0,0 \%$ \\
\hline $8^{\circ}$ ou mais & $19,4 \%$ \\
\hline Não respondeu & $11,1 \%$ \\
\hline Sim & $2,8 \%$ \\
\hline Não & $61,1 \%$ \\
\hline Questão 3 - Vó possui algum domínio prévio do assunto abordado pelas peças? \\
\hline Sim & $36,1 \%$ \\
\hline Não & $100,0 \%$ \\
\hline Questão 5 - Você acha que as peças deveriam continuar a serem utilizadas na disciplina? \\
\hline Não respondeu & $0,0 \%$ \\
\hline Sim & $2,8 \%$ \\
\hline Não & $5,6 \%$ \\
\hline
\end{tabular}

Fonte: os autores.

Tabela 2 - Resultados das questões fechadas do questionário com uso de escala de 1 a 5.

\begin{tabular}{|c|c|c|c|c|c|}
\hline \multirow{2}{*}{ Alternativas } & \multicolumn{5}{|c|}{ Questões } \\
\cline { 2 - 6 } & 4 & 6 & 7 & 9 & 10 \\
\hline 1 & $0,0 \%$ & $0,0 \%$ & $0,0 \%$ & $0,0 \%$ & $2,8 \%$ \\
\hline 2 & $0,0 \%$ & $2,8 \%$ & $0,0 \%$ & $0,0 \%$ & $0,0 \%$ \\
\hline 3 & $0,0 \%$ & $2,8 \%$ & $0,0 \%$ & $2,8 \%$ & $0,0 \%$ \\
\hline 4 & $30,6 \%$ & $19,4 \%$ & $5,6 \%$ & $52,8 \%$ & $27,8 \%$ \\
\hline 5 & $69,4 \%$ & $75,0 \%$ & $94,4 \%$ & $44,4 \%$ & $69,4 \%$ \\
\hline
\end{tabular}

Fonte: os autores.

Tabela 3 - Média das alternativas das questões fechadas do questionário com uso de escala de 1 a 5.

\begin{tabular}{|c|c|c|c|c|c|}
\hline Alternativas & 1 & 2 & 3 & 4 & 5 \\
\hline Médias & $0,60 \%$ & $0,60 \%$ & $1,10 \%$ & $27,20 \%$ & $70,60 \%$ \\
\hline
\end{tabular}

Fonte: os autores.

Por fim, na questão aberta, foi solicitado que os estudantes deixassem sugestões para melhorias, tendo sido destacadas as seguintes: "Colar os imãs com uma cola melhor. Em algumas peças estavam soltando", "Os imãs menores desprendem mais fácil das peças", "Colocar imãs um pouco mais fortes" e "Fazer peças demonstrando mais situações".

Cada um dos itens do questionário se encontra representado graficamente da Figura 16 até a Figura 25. 
Figura 16 - Respostas do item 1 do questionário.

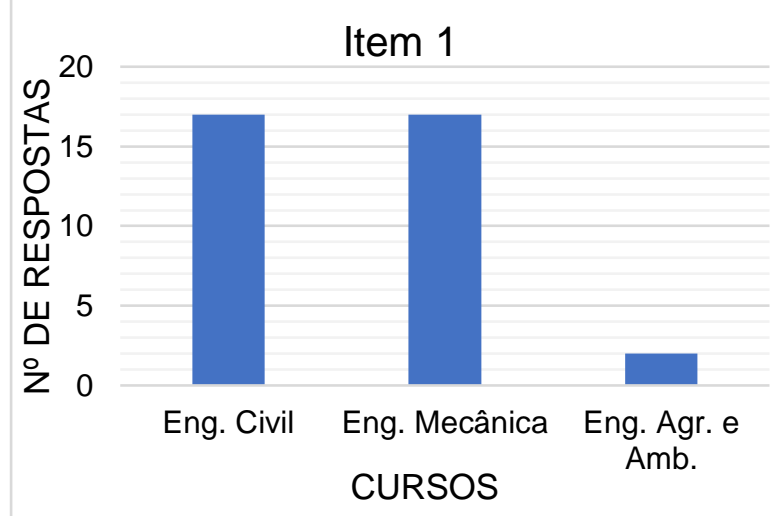

Fonte: os autores.

Figura 18 - Respostas do item 3 do questionário.

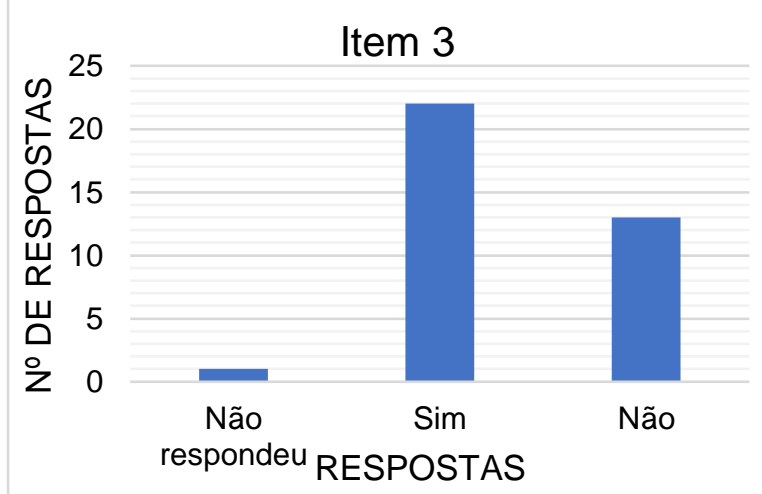

Fonte: os autores.

Figura 20 - Respostas do item 5 do questionário.

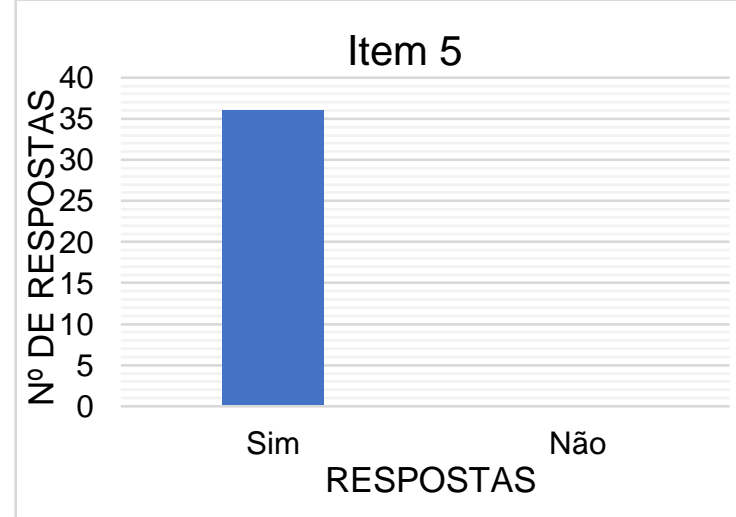

Fonte: os autores.
Figura 17 - Respostas do item 2 do questionário.

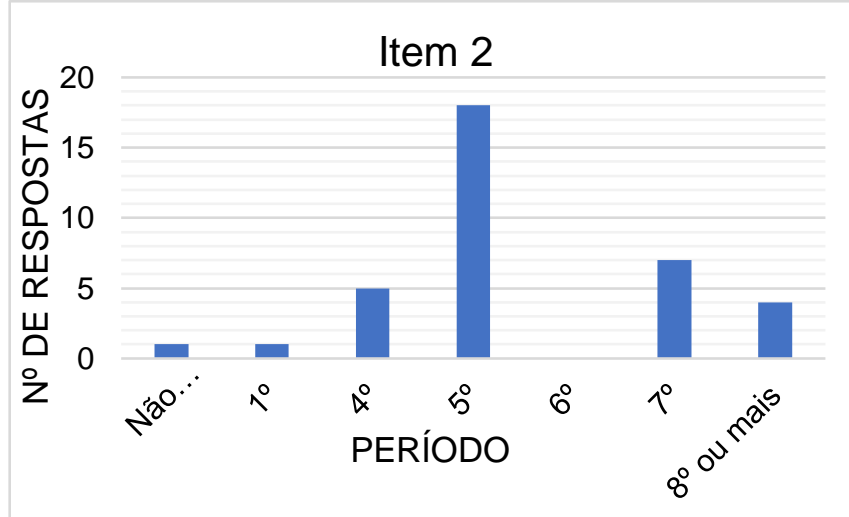

Fonte: os autores.

Figura 19 - Respostas do item 4 do questionário.

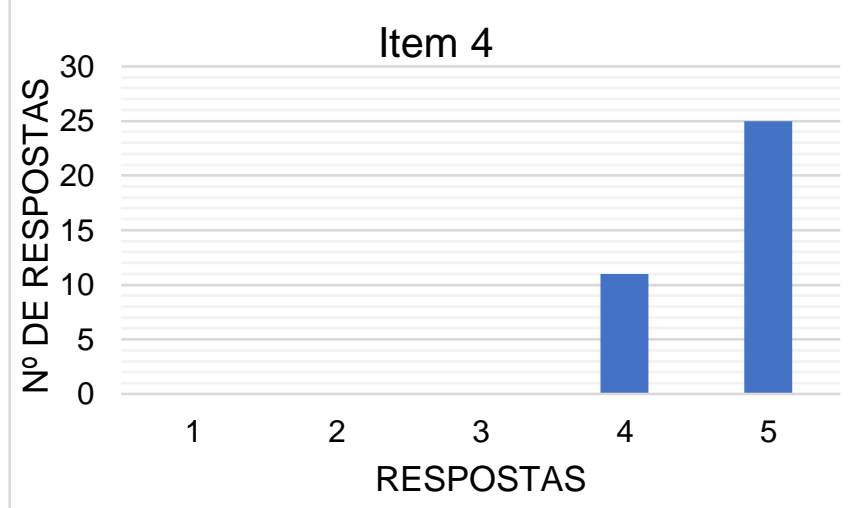

Fonte: os autores.

Figura 21 - Respostas do item 6 do questionário.

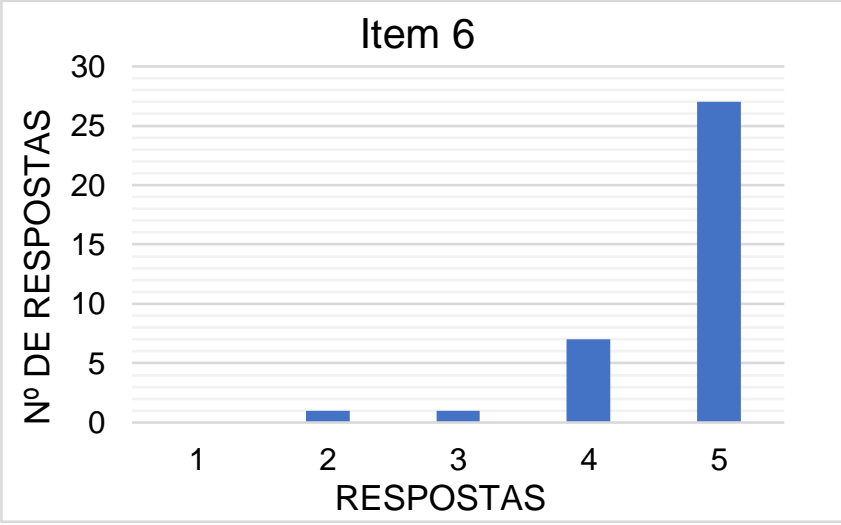

Fonte: os autores. 
Figura 22 - Respostas do item 7 do questionário.

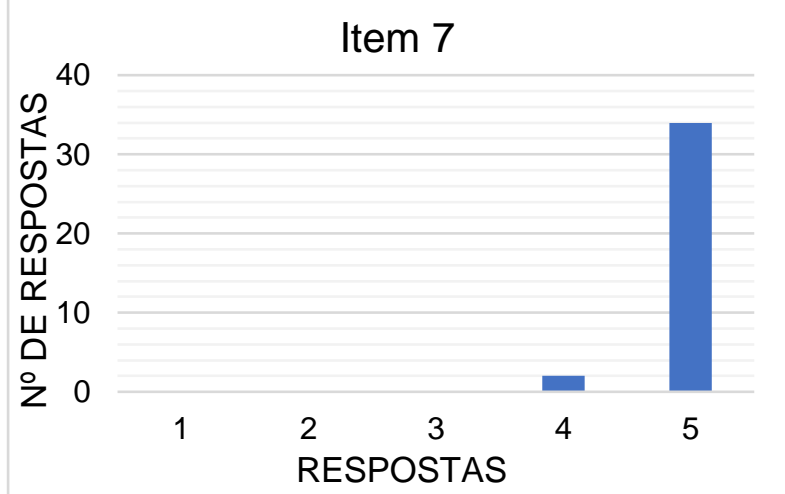

Fonte: os autores.

Figura 24 - Respostas do item 9 do questionário.

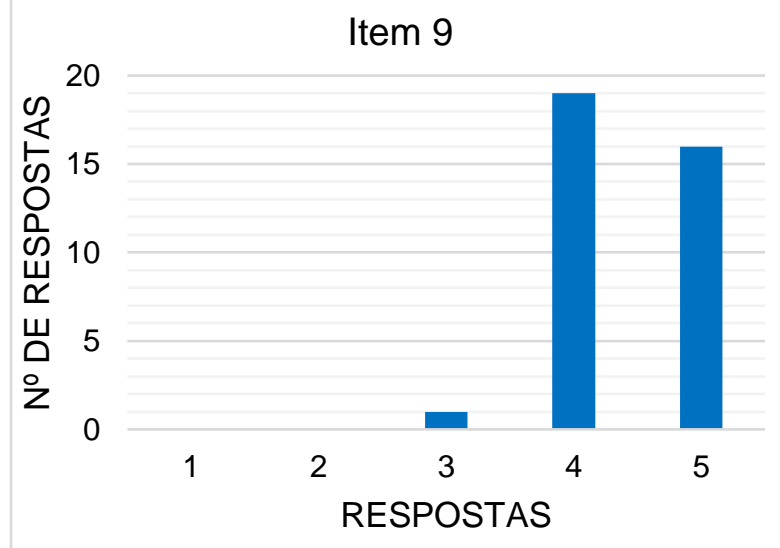

Fonte: os autores.
Figura 23 - Respostas do item 8 do questionário.

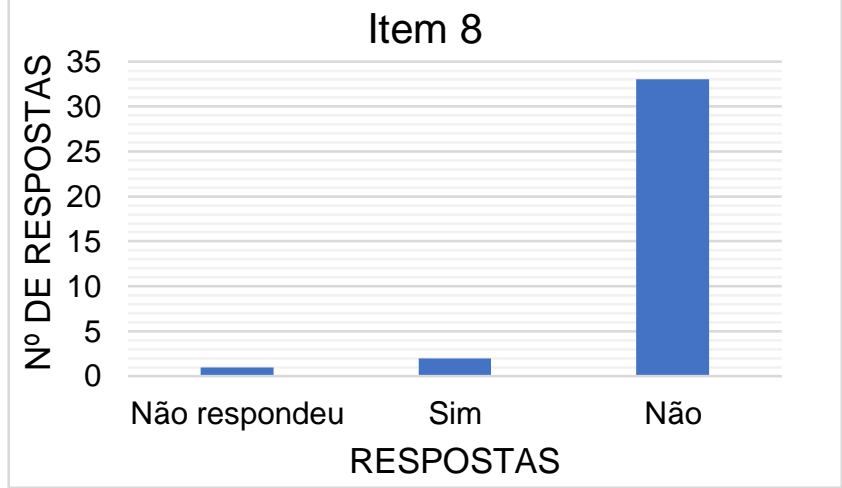

Fonte: os autores.

Figura 25 - Respostas do item 10 do questionário.

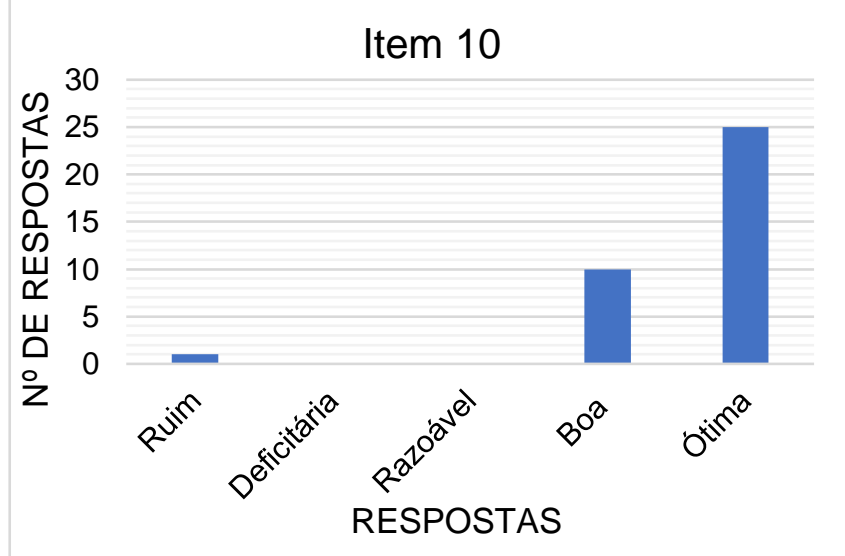

Fonte: os autores.

\section{CONSIDERAÇÕES FINAIS}

O projeto envolvendo a modelagem e impressão 3D de peças táteis no Laboratório de Resistência dos Materiais, para uso na disciplina CIV 150 - Resistência dos Materiais I da Universidade Federal de Viçosa, foi comprovadamente eficaz, a partir da análise dos resultados, em seu intuito de facilitar a visualização e entendimento dos esforços que surgem nos diferentes tipos de ligações estruturais, bem como o entendimento de conceitos básicos e fundamentais para disciplinas futuras de estruturas dos cursos de engenharia.

Além disso, verificou-se que o uso de modelos físicos foi eficiente, tendo a continuidade de seu uso sido encorajada pelos próprios estudantes, que também recomendaram o constante aprimoramento da prática.

\section{REFERÊNCIAS}

AGUIAR, L. C. D. Um processo para utilizar a tecnologia de impressão 3D na construção de instrumentos didáticos para o ensino de ciências. 2016. Dissertação (Mestrado em Educação para Ciência) - Universidade Estadual Paulista, 2016. 
BARRETO, M. A. M. Ensinando a ensinar - a importância do modelo na formação de professores. Revista Práxis, n. 1, p. 25-30, jan. 2009.

BEER, F.P.; JOHNSTON Jr E. R., Mecânica dos materiais. 5a ed. AMGH Editora Ltda, São Paulo, 2011.

BRENDLER, C. F; VIARO, F. S.; BRUNO, F. B.; TEIXEIRA, F. G.; SILVA, R. P. Recursos Didáticos Táteis Para Auxiliar a Aprendizagem de Deficientes Visuais. Educação Gráfica, v. 18, n. 03, p. 142-157, 2014.

HIBBELER, R. C. Estática - Mecânica para Engenharia, 12ª ed. São Paulo: Pearson Education do Brasil, 2010.

KODAMA, H. Automatic method for fabricating a three dimensional plastic model with photohardening polymer. Review of Scientific Instruments, v. 52, n. 11, p. 1770-1773, 1981.

MARTINS, V. H. C. Impressão 3D: uma abordagem de produção mais limpa? Dissertação (Mestrado em Engenharia Industrial) - Universidade do Minho - Escola de Engenharia, 2017.

OLIVEIRA, M. S. Modelo estrutural qualitativo para pré-avaliação do comportamento de estruturas metálicas. Dissertação (Mestrado em Engenharia Civil) - Universidade Federal de Ouro Preto, 2008.

ONISAKI, H. H. C; VIEIRA, R. M. B. Impressão 3D e o desenvolvimento de produtos educacionais. Revista de Estudos e Pesquisa Sobre Ensino Tecnológico, v. 05, n. 10, p. 128-137, mar. 2019.

PALAIO, S. C. S.; ALMEIDA, M. V. L; PATREZE, C. M. Desenvolvimento de modelos impressos em 3D para o ensino de ciências. Ensino de Ciências e Tecnologia em Revista, v. 8, n. 3, p. 70-82, set - dez. 2018.

PFEIL, W; PFEIL, M. Estruturas de aço: Dimensionamento Prático. 8 ${ }^{\underline{a}}$ ed. LTC, Rio de Janeiro, 2009.

PINHEIRO, A. C. F. B, Estruturas Metálicas: Cálculo, Detalhes, Exercícios e Projetos. 2ª ed. Editora Edgard Blucher, São Paulo, 2005.

QUEIROZ, J. H. M; SILVA, M. F. A; GOMES, H. P. R. Aplicação de impressões 3D como recurso didático para o ensino do componente curricular estruturas de aço na UFERSA - CMPF. Revista de Ensino de Engenharia, v. 39, p. 70-79, 2020.

RABELLO, Y. C. P; LEITE, M. A. D. F. D. Considerações sobre o Ensino e Aprendizagem de Estrutura nas Escolas de Arquitetura. Sistemas Estruturais em Arquitetura, n. 15, p. 1-14, 2015.

SARAMAGO, R. C. P. Ensino de estruturas nas escolas de arquitetura no Brasil. 2011. Dissertação (Mestrado em Arquitetura e Urbanismo) - Universidade de São Paulo, 2011.

TIMOSHENKO S.P. History of Strength of Materials. Dover Publications, New York, 1983. 


\title{
DEVELOPMENT OF STRUCTURAL MODELS FOR DIDACTICS IMPROVEMENT IN STRENGTH OF MATERIALS
}

\begin{abstract}
In engineering education at universities, it is essential to use a demonstration of the association between theory and practice, presenting real situations experienced by professional engineers. This focus needs to be improved in the Strength of Materials course, correlating the theoretical equations with the use of structural physical models. Therefore, the objective of this work was to create structural connections to provide students with an explanation of the theory and to facilitate the understanding of the concepts of applied loads, stresses, critical section, gross area and net area. Parts that commonly represent structures were modeled using AutoCAD $3 D$ software and then produced using the $3 D$ printing technique. After finalized, they were used for classroom explanations for students of Strength of Materials, defining and clarifying the concepts of the course. A questionnaire was applied to 36 students to assess the effectiveness of the methodology, with the majority of courses in Civil and Mechanical Engineering, taking the 5th period and with prior knowledge in the subject. Most students considered the parts to be good or excellent for theoretical understanding and considered that the parts should continue to be used in classes. Therefore, it was noticed that the models facilitated the understanding of the stress in different connections, as well as basic and fundamental concepts for future courses of structures. In addition, the use of practical and expository classes was efficient and should continue to be carried out.
\end{abstract}

Keywords: Education, Engineering, Structures, Strength of Materials. 